when the substituent is a halogen, while, with the substituent in the $p$-position, complications arise, as anticipated, from the operation of electromeric effects, and in a number of Class $B$ reactions the term in $\mu^{2}$ changes sign, an observation for which there was no obvious explanation.

We wish now to suggest that, while the equation $E=E_{0}-C\left(\mu-a \mu^{2}\right)$ applies to reactions of Class $A$, the correct expression for Class $B$ reactions may be $E=E_{0}+C\left(\mu+a_{\mu}{ }^{2}\right)$. Assuming this expression, the halogens as a group behave in accordance with the dipole moments of $\mathrm{C}_{\mathbf{8}} \mathrm{H}_{5} \mathrm{X}$, while the 'inclined' groups are exceptional. The new view is based, in fact, on the probability (kindly pointed out to us by Prof. Ingold) that the 'effective polarity' of these groups is represented not by the measured dipole moment but by the component in the plane of the nucleus. The calculation of the angle of inclination for $-\mathrm{OCH}_{3}$, from results where complications appear to be absent ${ }^{5}$, gives the value $112^{\circ}$ or $104.5^{\circ}$, according as the value of $u$ for anisole is taken as -0.8 or -1.2 Debye units. This may be compared with the angle suggested for singly-linked oxygen ${ }^{6}$ and the vertical angle for water ${ }^{7}$

No clear distinction can at present be drawn between the possibility outlined above and that suggested previously, but it is hoped to obtain further information from experiments now proceeding at these laboratories.

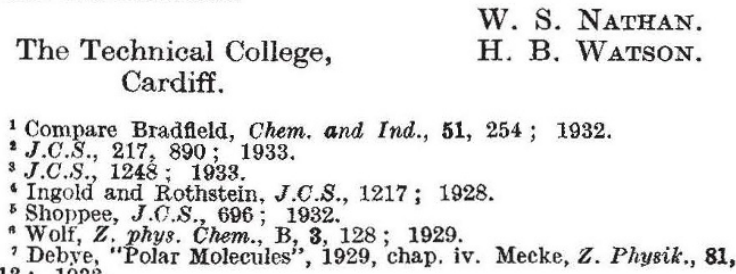
Cardiff.

W. S. Nathan.

H. B. Watson.

Compare Bradfleld, Chem. and Ind., 51, 254 ; 1932.

2 J.C.S., 217,$890 ; 1933$.

J.C.S., 1248 : 1933 .

- Ingold and Rothstein, J.C.S., 1217; 1928.

'Shoppee, J.C.S., 696; 1932 .

"Wolf, $Z$, phys. Chem., B, 3. 128 ; 1929.

'Debve, "Polar Molecules", 1929, chap. iv. Mecke, Z. Physik., 81, $313 ; 1933$.

\section{The Infinite and Eternal Energy}

THE quotation for which Mr. Donald Murray asks in Nature of February 24 is in Herbert Spencer's "Principles of Sociology", Part 6-Ecclesiastical Institutions, Chap. 16-Religious Retrospect and Prospect. It there reads as follows: "But one truth must grow ever clearer-the truth that there is an Inscrutable Existence everywhere manifested, to which he [the man of science] can neither find nor conceive either beginning or end. Amid the mysteries which become the more mysterious the more they are thought about, there will remain the one absolute certainty, that he is ever in presence of an Infinite and Eternal Energy, from which all things proceed."

It first appeared in January 1884, when this chapter of the "Sociology" was published as the first article in the Nineteenth Century. It was, I think, mainly responsible for the attack made upon Spencer by the late Mr. Frederic Harrison, the controversy between him and Spencer lasting almost throughout that year. In the course of the controversy, Mr. Harrison had referred to the Inscrutable Power as "the All-Nothingness", and Spencer replied in July : "So far from regarding that which transcends phenomena as the 'All-Nothingness', I regard it as the All-Being. Everywhere I have spoken of the Unknowable as the Ultimate Reality-the sole existence; all things present to consciousness being but shows of it." The entire controversy was issued in book form in America, at the insistent request of Spencer's American friend Prof. I. L. Yeomans, but an objection raised by Mr. Harrison so incensed Spencer that he wired to his New York publishers ordering the book to be withdrawn and the plates to be destroyed. It was unfortunate, for the whole incident made much clearer the positive aspect of Spencer's doctrine concerning the Ultimate Cause, as opposed to the negative aspect so unduly enlarged upon by his opponents.

\section{8, Stanley Road, \\ Woodford, E.18.}

Feb. 26.

[Several other correspondents, for whose letters we cannot find space, have also identified the quotation.-Ed. NATURE.]

\section{Uniformity in Bibliographic Particulars}

In the library of the John Innes Institution, and presumably in other scientific libraries, the indexing of 'separates' has become a formidable task. It is made more laborious where the particulars given of the source of the paper are misleading or incomplete. Editors will not, I am sure, be unwilling to consider the needs of the librarian, and I therefore venture on some suggestions.

First, the bibliographical particulars should be readily available on the cover or front page of the separate. (It is not necessarily the business of the person making the index cards to read the papers.) Secondly, no irrelevant matter should appear. The citation should be essentially as follows :

Name of author; title of paper; year; name of journal; volume; page references. (The pagination should be unaltered.)

Although there are a number of journals which adhere to this standard practice, too many others deviate from it in one way or another. The most usual deviations are the following :-

(1) Separates are sent out in blank covers, or in covers bearing the name of the journal but no other particulars.

(2) The title, etc., is given on the cover, but the page references omitted.

(3) The name of the journal is followed by the day, month and year of publication, and the volume and page references omitted; or the session (in the case of Proceedings) is given, and the year omitted.

(4) The paper is re-paginated, and the original page references not only omitted but also unascertainable.

(5) The cover is like that of the parent journal, and the name of the author of the paper either has to compete with that of the editor of the journal, or does not appear on the front page at all.

To take these points in order : (1) may be due to economy, which does not permit of a separately printed cover. It would cost no more and would suit most of us better to have such a paper without a cover, but with full particulars at the head of the first page. (2) is due to lack of foresight, as it is scarcely any more trouble for the printer to add the page references when printing the title; but in their absence every recipient of the separate who keeps a card-index has to waste time looking inside. (3) shows a lack of foresight that is even more depressing, as one cannot cite the complete reference without undertaking 